\title{
ON PRIMARY BANACH SPACES
}

\author{
BY P. G. CASAZZA, C. A. KOTTMAN AND BOR-LUH LIN
}

Communicated by Richard R. Goldberg, September 15, 1975

A Banach space $X$ is called primary (resp. prime) if for every projection $P$ on $X, P X$ or $(I-P) X$ (resp. $P X$ with $\operatorname{dim} P X=\infty$ ) is isomorphic to $X$. It is well known that $c_{0}$ and $l_{p}, 1 \leqslant p \leqslant \infty$, are prime spaces [5], [8], but it is an open question whether there are other prime Banach spaces. However, it is known that $C[0,1][7]$ and $L_{p}[0,1], 1<p<\infty[1]$, are primary, and in the recent Special Seminar on Functional Analysis at Urbana, Illinois, August, 1975 , it is announced [2] that $C(K)$ is primary for any countable compact metric space $K$. For a discussion on prime and primary Banach spaces, we refer to [6].

For a Banach sequence space $\left(E,\|\cdot\|_{E}\right)$ and a sequence of Banach spaces $\left\{X_{n}\right\}$, we shall let $\left(X_{1} \oplus X_{2} \oplus \cdots\right)_{E}$ be the Banach space of all sequences $\left\{x_{n}\right\}$ such that $x_{n} \in X_{n}, n=1,2, \ldots$ and $\left(\left\|x_{1}\right\|,\left\|x_{2}\right\|, \ldots\right) \in E$ with the norm $\left\|\left\{x_{n}\right\}\right\|=\left\|\left(\left\|x_{1}\right\|,\left\|x_{2}\right\|, \ldots\right)\right\|_{E}$.

A basis $\left\{e_{n}\right\}$ in a Banach space $X$ is called symmetric (cf. [10]) if every permutation $\left\{e_{\pi(n)}\right\}$ of $\left\{e_{n}\right\}$ is a basis of $X$, equivalent to $\left\{e_{n}\right\}$. For a basis $\left\{e_{n}\right\}$ of a Banach space $X$, we shall let $X_{n}$ be the linear span of $e_{1}, e_{2}, \ldots, e_{n}$ in $X$.

MAIN TheOREM. Let $X$ be a Banach space with symmetric basis $\left\{e_{n}\right\}$. Then the following spaces are primary.

(i) $(X \oplus X \oplus \cdots)_{l_{p}}, 1<p<\infty$, where $X$ is not isomorphic to $l_{1}$.

(ii) $\left(X_{1} \oplus X_{2} \oplus \cdots\right)_{l_{p}}, 1<p<\infty$, and $\left(X_{1} \oplus X_{2} \oplus \cdots \cdot\right)_{c_{0}}$.

(iii) $\left(l_{\infty} \oplus l_{\infty} \oplus \cdots\right)_{l_{p}}, 1 \leqslant p \leqslant \infty$, and $\left(l_{\infty} \oplus l_{\infty} \oplus \cdots \cdot\right)_{c_{0}}$.

Different techniques are needed in each of the three cases, and the cases $p=1$ or when $X$ is isomorphic to $l_{1}$ have to be treated separately. The proof for (i) is similar to the technique developed in [3]. To prove (ii), we use Ramsey's combinatorial lemma [9] and the following

LEMmA. Let $M=\left\{m_{i}\right\}$ be a sequence of positive integers such that $\lim \sup m_{i}=\infty$. Then there exist rearrangements of $M$ and the set of positive integers $N$ into double sequences $\left\{m_{1}^{\prime}, m_{2}^{\prime}, \ldots ; m_{1}^{\prime \prime}, m_{2}^{\prime \prime}, \ldots\right\}$ and $\left\{n_{1}^{\prime}, n_{2}^{\prime}\right.$, $\left.\ldots ; n_{1}^{\prime \prime}, n_{2}^{\prime \prime}, \ldots\right\}$ such that $m_{i}^{\prime}=n_{2 i-1}^{\prime}+n_{2 i}^{\prime}$ and $m_{2 i-1}^{\prime \prime}+m_{2 i}^{\prime \prime}=n_{i}^{\prime \prime}, i=$ $1,2, \ldots$

AMS (MOS) subject classifications (1970). Primary 46B15. 
Corollary. Let $X$ be a Banach space with symmetric basis and let $\left\{B_{n}\right\}$ be a sequence of Banach spaces with $\operatorname{dim} B_{n}=n, n=1,2, \ldots$ If there exists a constant $K$ such that the Banach-Mazur distance

$$
d\left(B_{n} \oplus B_{m}, B_{n+m}\right)=\inf \left\{\|T\|\left\|T^{-1}\right\|: T: B_{n} \oplus B_{m} \rightarrow B_{n+m}\right.
$$

linear isomorphism\}

$$
\leqslant K
$$

for all $n, m=1,2, \ldots$, then $\left(B_{1} \oplus B_{2} \oplus \cdots\right)_{X}$ is isomorphic to $\left(B_{m_{1}} \oplus B_{m_{2}} \oplus \cdots \cdot\right)_{X}$ for all $\left\{m_{i}\right\}$ with $\lim \sup m_{i}=\infty$.

REMARK. When $X=l_{p}, 1<p<\infty$, a similar result was stated in [4, Lemma 5].

The proof of (iii) consists of generalizing the technique used by Lindenstrauss [5] in proving that $l_{\infty}$ is prime and the following fact which is interesting in itself.

THEOREM 2. Let $X$ be a Banach space with symmetric basis. If $E$ is a Banach space which has a complemented subspace isomorphic to $X$, then for any bounded linear operator $T: E \rightarrow E$, either $T E$ or $(I-T) E$ has a complemented subspace isomorphic to $X$.

By combining the techniques used to prove the Main Theorem and Theorem 2, we could obtain, for example,

THEOREM 3. Let $X$ be a Banach space with symmetric basis. If $E$ is a Banach space which has a complemented subspace isomorphic to $(X \oplus X \oplus \cdots \cdot)_{l_{p}}, 1<p<\infty\left(\right.$ resp. $\left.(X \oplus X \oplus \cdots \cdot)_{c_{0}}\right)$, then for any bounded linear operator $T: E \rightarrow E$, either $T E$ or $(I-T) E$ contains a complemented subspace isomorphic to $(X \oplus X \oplus \cdots \cdot)_{l_{p}}, 1<p<\infty$ (resp. $\left.(X \oplus X \oplus \cdot \cdot)_{c_{0}}\right)$.

Details of proofs will appear elsewhere.

\section{REFERENCES}

1. Dale Alspach, P. Enflo and E. Odell, On the structure of separable $L_{p}$ spaces, $1<p<\infty$ (to appear).

2. Dale Alspach and Y. Benjamini, On the primariness of $C(K)$ where $K$ is a countable compact metric space (in preparation).

3. P. G. Casazza and Bor-Luh Lin, Projections on Banach spaces with symmetric basis, Studia Math. 52 (1974), 189-193.

4. I. S. Ėidel šteìn and B. S. Mitjagin, Homotopy type of linear groups of two classes of Banach spaces, Funkcional. Anal. i Priložen. 4 (1970), no. 3, 61-72= Functional Anal. Appl. 4 (1970), 221-231. MR 49 \#6274d.

5. J. Lindenstrauss, On complemented subspaces of $m$, Israel J. Math. 5 (1967), 153-156. MR 36 \#5666.

6. - Decompositions of Banach spaces, Indiana Univ. Math. J. 20 (1971), 917-919. 
7. J. Lindenstrauss and A. Pelczyński, Contributions to the theory of the classical Banach spaces, J. Functional Analysis 8 (1971), 225-249. MR 45 \#863.

8. A. Pelczyński, Projections in certain Banach spaces, Studia Math. 19 (1960), 209-228. MR 23 \#A3441.

9. F. D. Ramsey, On a problem of formal logic, Proc. London Math. Soc. 30 (1929), 338-384.

10. I. Singer, Bases in Banach spaces. I, Die Grundlehren der math. Wissenschaften, Band 154, Springer-Verlag, Berlin and New York, 1970. MR 45 \#7451.

DEPARTMENT OF MATHEMATICS, UNIVERSITY OF ALABAMA, HUNTSVILLE, ALABAMA 35807

DEPARTMENT OF MATHEMATICS, OREGON STATE UNIVERSITY, CORVALLIS, OREGON 97331

DEPARTMENT OF MATHEMATICS, UNIVERSITY OF IOWA, IOWA CITY, IOWA 52242 